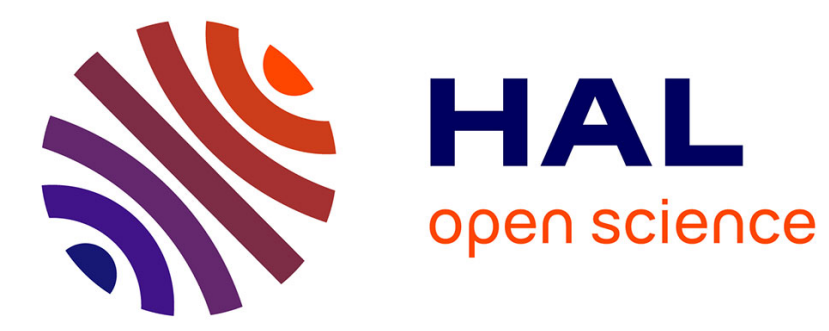

\title{
Dopamine and response selection: an Acute Phenylalanine/Tyrosine Depletion study
}

Céline Ramdani, Franck P. Vidal, Alain Dagher, Laurence Carbonnell, Thierry Hasbroucq

\section{To cite this version:}

Céline Ramdani, Franck P. Vidal, Alain Dagher, Laurence Carbonnell, Thierry Hasbroucq. Dopamine and response selection: an Acute Phenylalanine/Tyrosine Depletion study. Psychopharmacology, 2018, 235 (4), pp.1307-1316. 10.1007/s00213-018-4846-3 . hal-01763857

\section{HAL Id: hal-01763857}

\section{https://hal-amu.archives-ouvertes.fr/hal-01763857}

Submitted on 19 Apr 2018

HAL is a multi-disciplinary open access archive for the deposit and dissemination of scientific research documents, whether they are published or not. The documents may come from teaching and research institutions in France or abroad, or from public or private research centers.
L'archive ouverte pluridisciplinaire HAL, est destinée au dépôt et à la diffusion de documents scientifiques de niveau recherche, publiés ou non, émanant des établissements d'enseignement et de recherche français ou étrangers, des laboratoires publics ou privés. 


\title{
Dopamine and response selection: an Acute Phenylalanine/Tyrosine Depletion study
}

\author{
Céline Ramdani $^{1}$ (D) Franck Vidal $^{2} \cdot$ Alain Dagher $^{3} \cdot$ Laurence Carbonnell $^{4} \cdot$ Thierry Hasbroucq $^{2}$
}

\begin{abstract}
The role of dopaminergic system in decision-making is well documented, and evidence suggests that it could play a significant role in response selection processes. The N-40 is a fronto-central event-related potential, generated by the supplementary motor areas (SMAs) and a physiological index of response selection processes. The aim of the present study was to determine whether infraclinical effects of dopamine depletion on response selection processes could be evidenced via alterations of the $\mathrm{N}-40$. We obtained a dopamine depletion in healthy volunteers with the acute phenylalanine and tyrosine depletion (APTD) method which consists in decreasing the availability of dopamine precursors. Subjects realized a Simon task in the APTD condition and in the control condition. When the stimulus was presented on the same side as the required response, the stimulus-response association was congruent and when the stimulus was presented on the opposite side of the required response, the stimulus-response association was incongruent. The N-40 was smaller for congruent associations than for incongruent associations. Moreover, the N-40 was sensitive to the level of dopaminergic activity with a decrease in APTD condition compared to control condition. This modulation of the N-40 by dopaminergic level could not be explained by a global decrease of cerebral electrogenesis, since negativities and positivities indexing the recruitment of the primary motor cortex (anatomically adjacent to the SMA) were unaffected by APTD. The specific sensitivity of N-40 to ATPD supports the model of Keeler et al. (Neuroscience 282:156-175, 2014) according to which the dopaminergic system is involved in response selection.
\end{abstract}

Keywords Dopamine $\cdot$ Supplementary motor areas $\cdot$ Simon task $\cdot$ Electroencephalography $\cdot$ Response selection $\cdot$ Acute phenylalanine/tyrosine depletion: APTD

\section{Introduction}

Decision-making can be regarded as a set of cognitive processes that contribute to the production of the optimal alternative among a set of concurrently possible actions. The role of the dopaminergic system in human decision-making is well documented (e.g., Montague et al. 1996, 2004; Rogers 2011).

Céline Ramdani

celineramdani@hotmail.fr

1 Institut de Recherche Biomédicale des Armées, Brétigny-sur-Orge, France

2 Laboratoire de Neurosciences Cognitives, Aix-Marseille Univ/CNRS, Marseille, France

3 Montreal Neurological Institute and Hospital, McGill University, Montreal, Quebec, Canada

4 Institut de Médecine Navale du Service de Santé des Armées, Toulon, France
Response selection (i.e., the association of a specific action to a specific sensation) can be considered as the core process of decision-making (Keeler et al. 2014), and one can wonder whether the dopaminergic system is directly involved in this process. According to Keeler et al. (2014), the striatal direct pathway (D1 receptors subtype) would allow preparation for response selection, while the striatal indirect pathway (D2 receptor subtypes) would allow selection of the appropriate response within the prepared set of all possible responses, through. Keeler et al. (2014) called this system a "prepare and select" architecture.

The implication of the dopaminergic system in preparatory processes has been widely acknowledged in animals. Response preparation is impaired in rats after dopamine depletion (Brown and Robbins 1991).

Now, Yoon et al. (2015) went a step further showing that, during preparation, the activation of the dopaminergic system adjusts to the difficulty of the response selection to be performed after this preparation. 
In humans, taking advantage of the high iron concentration in the substantia nigra (SN) which reveals this structure as a relatively hypodense zone on T2*-weighted images (including EPI volumes), Yoon et al. (2015) accurately examined the activation of the SN during the 7.5-s preparatory period of a between-hand choice reaction time (RT) task. At the beginning of the preparatory period, a precue indicated which one of two (easy or difficult) stimulus-response associations should be applied when the response signal (RS) would be delivered, at the end of the preparatory period. The SN BOLD signal increased after the precue in both cases. However, whereas the BOLD signal returned to baseline towards the end of the preparatory period in the easiest of the two possible response selection conditions, this signal remained at high levels until the end of the preparatory period in the most difficult condition. Interestingly, no such an interaction could be evidenced in the neighboring subthalamic nucleus (STN); given the close functional relationships between STN and SN pars reticulata, the authors convincingly argued that the BOLD signal sensitivity to the difficulty of the selection process resulted from a sensitivity of the dopaminergic neurons of SN pars compacta to this manipulation. This interpretation is highly consistent with Keeler et al.'s (2014) model which assumes that the dopaminergic system plays a prominent role in response selection processes. Now, after the RS, that is in the period when response selection itself occurs, no differential effect could be evidenced, but this might easily be explained by the poor temporal resolution of fMRI method (RTs were about 550 and $600 \mathrm{~ms}$ only, in the easy and difficult conditions, respectively).

Evidencing a direct effect of the dopaminergic system on response selection processes themselves (which take place during the RT period) would lend direct additional support to Keeler et al.'s view that the dopaminergic system plays an essential role in response selection, not only in preparing for its difficulty (Yoon et al. 2015) but also in carrying out response selection processes themselves; this was the aim of the present study which will be made explicit as follows.

Among the main targets of the basal ganglia (via the thalamus) are the supplementary motor areas (SMAs). Recent fMRI data did demonstrate that acute diet-induced dopamine depletion (APTD) impairs timing in humans by decreasing activity not only in the putamen but also in the SMAs (Coull et al. 2012), which role in motor as well as sensory timing is well documented (e.g., Coull et al. 2011).

SMAs are often assumed to play a prominent role not only in timing but also in response selection (e.g., Mostofsky and Simmonds 2008, for a review). Taking into account the sensitivity to dopamine depletion of the SMAs (Coull et al. 2012), one might therefore wonder, in the frame of Keeler et al.'s (2014) model, whether their activities would also be impaired, by APTD during the reaction period of a RT task in which a response selection is required. Given the short time range of RTs, a high temporal resolution method is needed to address this question. EEG seems to be particularly adapted, since it is classically considered as having an excellent temporal resolution (Sejnowski and Churchland 1990).

During the reaction time of a between-hand choice RT task, an electroencephalographic (EEG) component has been evidenced in humans (the N-40; Vidal et al. 2011) right over the SMAs. Given that the N-40 peaks about $50 \mathrm{~ms}$ before the peak activation of the (contralateral) primary motor cortex involved in the response, it has been proposed that this component is an index of response selection which might arise from the SMAs. In accordance to this view, it has been shown that (1) that the N-40, although present in choice conditions was absent in a go/ no-go task, a task in which no response selection is required (Vidal et al. 2011); and (2) that the amplitude of the N-40 was modulated by the difficulty of the selection process, being smaller for easier selections (Carbonnell et al. 2013). Finally, tentative source localization performed with two independent methods (sLORETA and BESA), pointed to quite superficial medio frontal generators corresponding to the SMAs (Carbonnell et al. 2013).

If we admit that the N-40 is generated by the SMAs and index response selection, a convenient way to address the question of the involvement of the dopaminergic system in response selection processes consists in examining the sensitivity of the N-40 to APTD in a between-hand choice RT task quite similar to the one used by Yoon et al. (2015): we chose a Simon task (see Fig. 1, see Simon (1990) for a review).

Now, in between-hand choice RT tasks, the N-40 is followed by a transient (negative) motor potential (Deecke et al. 1976) revealing the build-up of the motor command in the (contralateral) primary motor areas (M1) controlling the responding hand (Arezzo and Vaughan 1980). Concurrently, a transient positive wave, reflecting motor inhibition and related to error prevention (Meckler et al. 2010), develops over (ipsilateral) M1 controlling the non-responding hand (Vidal et al. 2011). If one admits that these activities are not directly related to response selection, examining their (in)sensitivity to dopamine depletion allows examining the selectivity of the effects of this depletion (if present) on response selection processes.

In a previous study, we submitted subjects to APTD. Although we did evidence subtle behavioral effects that can be attributed to action monitoring impairments (Ramdani et al. 2015), we did not find any clear behavioral evidence of APTD-induced response selection impairment.

To evidence the role of the dopaminergic system in response selection, the present study was aimed at assessing whether infraclinical effects of dopamine depletion on response selection processes can be evidenced via selective alterations of the $\mathrm{N}-40$. 

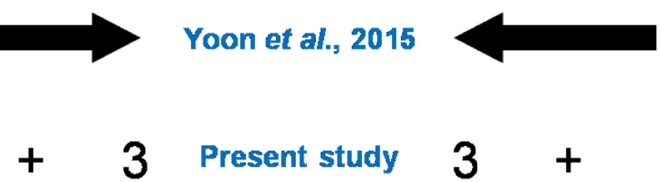

\section{Present study}
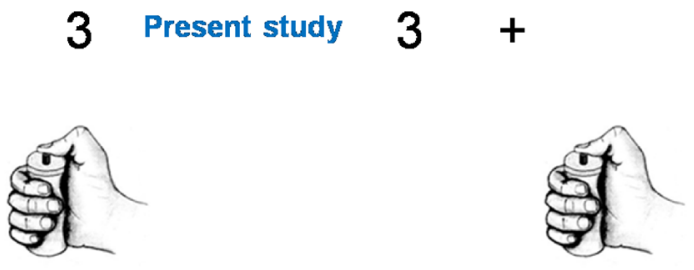

\section{CONGRUENT}

INCONGRUENT

Fig. 1 Schematic representation of the task used by Yoon et al. (2015) and the present task. Congruency in the Yoon et al. (2015) task was between the arrow direction and the response side and in the present task between stimulus position and response side

\section{Material and method}

The experimental procedure has been described in detail elsewhere (Ramdani et al. 2015), and only essential information is provided here.

Twelve healthy subjects participated in this experiment.

\section{Dopamine depletion}

Dopamine availability was decreased using the APTD method (McTavish et al. 1999; Leyton et al. 2000, 2004; NaganoSaito et al. 2008, 2012). The present experiment comprised two experimental sessions differing by the level of tyrosine and phenylalanine in the amino acid mixture: (i) the "placebo session": the subject performed the task after ingestion of a mixture containing 16 essential amino acids (including tyrosine and phenylalanine) and (ii) the "depleted session": the subject performed the task after the ingestion of the mixture without tyrosine and phenylalanine.

Plasma concentrations of phenylalanine, tyrosine, and other large neutral amino acids (LNAAs; leucine, isoleucine, methionine, valine, and tryptophane) were measured by HPLC with fluorometric detection on an Ultrasphere ODS reversephase column (Beckman Coulter) with ophtalaldehyde precolumn derivatization and amino-adipic acid as an internal standard. Plasma concentrations of tryptophan were measured by HPLC-FD on a Bondpak reverse-phase column (Phenomenex).

\section{Task and design}

Each subject performed both sessions, on separate days, at least 3 days apart. Subjects were not taking any medication at the time of the experiment. None of them had a history of mental or neurologic illness. They were asked not to take stimulating substances (e.g., caffeine or stimulant drugs) or alcohol the day and the night before both sessions. The day before each session, subjects ate a low protein diet provided by investigators and fasted after midnight. On the test days, subjects arrived at 8:30 a.m. at the laboratory and had blood sample drawn to measure plasma amino acid concentrations. They ingested one of the two amino acid mixtures at 9:00 a.m. in a randomized, double-blind manner. Peak dopamine reduction occurs during a period 4-6 h after ingestion of the two amino acid mixtures (Leyton et al. 2004). They were tested from 1:30 p.m. At 3:00 p.m., subjects had a second blood sample drawn to measure plasma amino acid concentrations.

The order of depleted and placebo sessions was counterbalanced between subjects.

Subjects performed a between-hand choice reaction time RT task.

A trial began with the presentation of a stimulus. The subjects' responses turned off the stimulus, and $500 \mathrm{~ms}$ later, the next stimulus was presented. If subjects had not responded within $800 \mathrm{~ms}$ after stimulus onset, the stimulus was turned off and the next stimulus was displayed $500 \mathrm{~ms}$ later.

At the beginning of an experimental session, subjects had one training block of 129 trials. Then, they were required to complete 16 blocks of 129 trials each. A block lasted about $2 \mathrm{~min}$. There was $1 \mathrm{~min}$ break between two blocks and $5 \mathrm{~min}$ break every four blocks. The training block was discarded from statistical analyses.

The structure of this between-hand choice RT task realized a Simon task (Simon 1990). The stimuli of this Simon task were the digits three, four, six, and seven presented either to the right or the left of a central fixation point. Half of the subjects responded with the right thumb on the right force sensor for even digits and with the left thumb on the left force sensor for odd digits; the other half performed the reverse mapping. When the stimulus was presented on the same side as the required response, the stimulus-response association was congruent. When the stimulus was presented on the side opposite to the required response, the stimulus-response association was incongruent. A block contained $50 \%$ of the congruent trials and $50 \%$ of the incongruent ones.

Yoon et al. (2015) (see Fig. 1) manipulated the complexity of the stimulus-response association by varying the spatial correspondence between the direction (right or left) indicated by a centrally presented arrow and the position (right or left) of the required response: on congruent associations, responses had to be given on the side indicated by the arrow, while on incongruent associations, responses had to be given on the opposite side. In the present Simon task, congruency was manipulated by varying the spatial correspondence between the position of the stimulus and the position of the required response, given that (1) as in the Yoon et al. (2015) study, congruency affects response selection processes (Hommel et al. 2004; Kornblum et al. 1999; Proctor and Reeve 1990) and (2) congruency affects the amplitude of the N-40 in a Simon task (Carbonnell et al. 2013). 
Subjects were asked to respond as fast and as accurately as possible.

RT was defined by the time interval between the stimulus onset and the mechanical response.

\section{Electrophysiological recordings and processing}

The electromyographic (EMG) activity of the flexor pollicis brevis (thenar eminence, inside base of the thumb) was recorded bipolarly by means of surface $\mathrm{Ag}-\mathrm{AgCl}$ electrodes, $6 \mathrm{~mm}$ in diameter, fixed about $20 \mathrm{~mm}$ apart on the skin of each thenar eminence. The recorded EMG signals were digitized online (bandwidth $0-268 \mathrm{~Hz}, 3 \mathrm{db} / \mathrm{octave}$, sampling rate $1024 \mathrm{~Hz}$ ), filtered off-line (high pass $=10 \mathrm{~Hz}$ ), and then, inspected visually (Van Boxtel et al. 1993). The EMG onsets were hand scored because human pattern recognition processes are superior to automated algorithms (see Staude (2001)). To overcome subjective influence on the scoring, the experimenter who processed the signals was unaware of the type of associations (congruent, incongruent) or session (placebo, APTD) to which the traces corresponded.

Electroencephalogram (EEG) and electro-oculogram (EOG) were recorded continuously from preamplified $\mathrm{Ag} /$ $\mathrm{AgCl}$ electrodes (BIOSEMI Active-Two electrodes, Amsterdam). For EEG, 64 recording electrodes were disposed according to the $10 / 20$ system with CMS-DRL as reference and ground (specific to the Biosemi acquisition system). A 65th electrode on the left mastoid served to reference the signal offline. Electrodes for vertical and horizontal EOG were at the Fp1 and below the left eye and at the outer canthus of the left and right eyes, respectively. The signal was filtered and digitized online (bandwidth 0-268 Hz, $3 \mathrm{db} /$ octave, sampling rate $1024 \mathrm{~Hz}$ ). EEG and EOG data were numerically filtered offline (high pass $=0.02 \mathrm{~Hz}$ ). No additional filtering was performed. Bipolar derivations were calculated offline for vertical and horizontal EOGs. Then, ocular artifacts were subtracted (Gratton et al. 1983). A trial-by-trial visual inspection of monopolar recordings allowed us to reject unsatisfactory subtractions and other artifacts.

The scalp potential data were segmented from $(-500)$ to (+500 ms) with the EMG onset as zero of time. Afterward, for each individual, scalp potential data were averaged time locked to the EMG onset. However, on scalp potential data, due to volume conduction effects, the N-40 is overlapped by large components generated by remote generators and by closer ones in the primary motor areas. Therefore, it hardly shows up on scalp potential recordings (Vidal et al. 2011).

The surface Laplacian (SL) transformation (see Carvalhaes and de Barros (2015) for theory and methods), acting as a high-pass spatial filter (Nuñez 1989), is very efficient in attenuating volume conduction effects (Giard et al. 2014; Kayser and Tenke 2015). Because of this property, the SL transformation allows unmasking the $\mathrm{N}-40$, by removing spatial overlap between this component and other ones. Therefore, the Laplacian transformation was applied on each individual scalp potential average, obtained for each subjects in each condition (congruent and incongruent), and each session (placebo and APTD); surface Laplacian was estimated after spherical spline interpolation with four as the degree of spline and a maximum of $10^{\circ}$ for the Legendre polynomial, according to the method of Perrin et al. (1987).

$\mathrm{N}-40$ At the FCz electrode, the N-40 begins to develop about $70 \mathrm{~ms}$ and peaks about $20 \mathrm{~ms}$ before EMG onset. The slopes of the linear regression of this wave were computed for each subject from -70 to $-20 \mathrm{~ms}$, so within a $50-\mathrm{ms}$ time window. The slopes of the N-40 were determined for "pure" correct trials only. These values were then submitted to repeatedmeasures canonical analyses of variance (ANOVA). The ANOVA involved two within-subjects factors: session (placebo, APTD) and congruency (congruent, incongruent) for mean results. Contrary to stimulus-locked data, when studying response-locked averages, the choice of the appropriate baseline is always problematic. To circumvent the problem, peakto-peak measures are often used, as they are baseline free. They may be conceived of as a crude slope measure. However, mean slopes can be estimated by computing the linear regression line by the least squares method, in an interval of interest. In this case, slope analysis has certain advantages over amplitude analysis: (i) they are also independent of the baseline and (ii) they give morphological information on the polarity of the curves in delimited time windows and are less variable than amplitude measures (Meckler et al. 2010).

Activation/inhibition pattern For correct trials, we analyzed EEG activities over the primary sensory-motor area (SM1) contralateral and ipsilateral to the response (over $\mathrm{C} 3$ and $\mathrm{C} 4$ electrodes): we measured the slopes computed by linear regression in a specific time window of $50 \mathrm{~ms}(-30 \mathrm{~ms} ; 20 \mathrm{~ms})$ (e.g., Meckler et al. 2010). These mean values of slope were submitted to an ANOVA involved two within-subjects factors: session (placebo, APTD) and congruency (congruent, incongruent).

\section{Results}

\section{Amino acid plasmatic concentrations}

For phenylalanine (see Table 1), the ANOVA revealed an effect of the session $(F(1,11)=37.49 ; p=0.000075)$ and no effect of the time of the drawn $(F(1,11)=0.13 ; p=0.73)$. These two factors interacted $(F(1,11)=119.81 ; p=$ $0.000000)$, signaling that the session affected the samples drawn at the end of the testing session, $6 \mathrm{~h}$ after ingestion $(F$ $(1,11)=65.84 ; p=0.000006)$, but not the samples drawn 
Table 1 Amino acid plasmatic concentrations of phenylalanine

\begin{tabular}{lll}
\hline Amino acid & $\begin{array}{l}\text { Before the absorption } \\
\text { of the mixture }\end{array}$ & $\begin{array}{l}\text { After the absorption } \\
\text { of the mixture }\end{array}$ \\
\hline Phenylalanine $(\mu \mathrm{mol} / \mathrm{l})$ placebo & $60.3 \pm 3.2$ & $106.8 \pm 6.1^{*}$ \\
Phenylalanine $(\mu \mathrm{mol} / \mathrm{l})$ depleted & $59.8 \pm 3.5$ & $17.4 \pm 3.6^{*}$ \\
Tyrosine $(\mu \mathrm{mol} / \mathrm{l})$ placebo & $74.4 \pm 4.1$ & $272.7 \pm 10.8^{*}$ \\
Tyrosine $(\mu \mathrm{mol} / \mathrm{l})$ depleted & $71.7 \pm 4.4$ & $20.5 \pm 4.4^{*}$ \\
\hline
\end{tabular}

before ingestion $(F(1,11)=0.016 ; p=0.902)$. For tyrosine (see Table 1), the ANOVA revealed a main effect of the session $(F(1,11)=68.91 ; p=0.000005)$ and a main effect of time $(F(1,11)=17.95 ; p=0.0014)$. These two factors interacted $(F(1,11)=68.83 ; p=0.000005)$, indicating that the session affected tyrosine levels at the end of the session $(F(1,11)=71.16 ; p=0.000004)$ but not prior to ingestion $(F$ $(1,11)=0.24 ; p=0.631)$.

In sum, plasma concentrations of tyrosine and phenylalanine were significantly lower for the depleted session than for the placebo session.

\section{Reaction time of correct responses}

There was a main effect of congruency of $13 \mathrm{~ms}$ (congruent $408 \mathrm{~ms}$, incongruent $421 \mathrm{~ms}, F(1,11)=57.58 ; p=0.00001)$ but no effect of session (placebo $414 \mathrm{~ms}$; depleted $416 \mathrm{~ms}, F$ $(1,11)=0.056 ; p=0.817)$. These two factors did not interact on mean RT $(F(1,11)=0.116 ; p=0.739)$.

\section{Error rate}

There was a non-significant trend for an increase of error rate on incongruent stimulus-response associations (7.28\%) compared to congruent stimulus-response associations $(5.79 \%)$ $(F=3.70 ; p=0.081)$. The error rate was not statistically different for the placebo $(6.62 \%)$ and depleted $(6.45 \%)$ sessions $(F(1,11)=0.123 ; p=0.732)$. There was no interaction between congruency and session $(F(1,11)=0.026 ; p=0.874)$.

\section{N-40 (Fig. 2)}

Only data obtained on correct trials have been analyzed.

As expected from Carbonnell et al. (2013), the slope of the $\mathrm{N}-40$ was steeper on the incongruent $\left(-57.42 \mu \mathrm{V} / \mathrm{cm}^{2} / \mathrm{ms}\right)$ than on the congruent condition $\left(-24.50 \mu \mathrm{V} / \mathrm{cm}^{2} / \mathrm{ms}\right)(\mathrm{size}$ effect on steepness $-32.92 \mu \mathrm{V} / \mathrm{cm}^{2} / \mathrm{ms}, F(1,11)=5.41, p=$ $0.040)$. The congruency effect observed on slopes of the N-40 was attributed to the more demanding selection on incongruent stimulus-response associations as compared to congruent stimulus-response associations. Moreover, the slope of the $\mathrm{N}-40$ was also steeper on placebo $\left(-59.39 \mu \mathrm{V} / \mathrm{cm}^{2} / \mathrm{ms}\right)$ than on the APTD session $\left(-22.54 \mu \mathrm{V} / \mathrm{cm}^{2} / \mathrm{ms}\right.$ ) (size effect on steepness $\left.-36.85 \mu \mathrm{V} / \mathrm{cm}^{2} / \mathrm{ms}, F(1,11)=5.50, p=0.039\right)$.
These two factors (congruency and sessions) did not interact $(F(1,11)=0.030 ; p=0.865)$.

\section{Activation/inhibition pattern (Fig. 3)}

Inspection of the Laplacian traces reveals that, for all conditions, a negativity/positivity pattern developed before EMG onset over the controlateral and ipsilateral M1s respectively.

As expected from Vidal et al. (2011), over contralateral M1 (over controlateral electrode), we observed a negative wave peaking about EMG onset while over the ipsilateral M1 (over ipsilateral electrode), we observed a positive wave.

Regarding contralateral negativity, there was no effect of congruency (congruent condition $-210.37 \mu \mathrm{V} / \mathrm{cm}^{2} / \mathrm{ms}$ and incongruent condition $-224.19 \mu \mathrm{V} / \mathrm{cm}^{2} / \mathrm{ms} ; F(1,11)=$ $0.67 ; p=0.429$ ) or main effect of the session (placebo session $-213.10 \mu \mathrm{V} / \mathrm{cm}^{2} / \mathrm{ms}$, APTD session $-221.47 \mu \mathrm{V} / \mathrm{cm}^{2} / \mathrm{ms} ; F$ $(1,11)=0.066 ; p=0.802)$. These two factors did not interact $(F(1,11)=1.18, p=0.299)$.

Regarding ipsilateral positivity, there was neither an effect of congruency (congruent condition $102.51 \mu \mathrm{V} / \mathrm{ms}$ and incongruent condition $110.26 \mu \mathrm{V} / \mathrm{ms} ; F(1,11)=0.349 ; p=0.566)$ nor an effect of session (placebo session $109.53 \mu \mathrm{V} / \mathrm{ms}$, APTD session $103.25 \mu \mathrm{V} / \mathrm{ms} ; F(1,11)=0.182 ; p=0.677)$. These two factors did not interact $(F(1,11)=0.098 ; p=0.759)$.

\section{Discussion}

The present study reproduces already available data: (1) RTs were longer on congruent than on incongruent trials, revealing the existence of a Simon effect; (2) an activation/inhibition pattern developed over M1s before the response (Vidal et al. 2011; Van de Laar et al. 2012; Amengual et al. 2014); (3) this activation/inhibition pattern was preceded by an N-40 (Vidal et al. 2011; Amengual et al. 2014), which is in line with the notion that N-40 index response selection processes, upstream to response execution as manifested by contralateral M1 activation; (4) the amplitude of the N-40 depended on congruency, being larger on congruent than on incongruent associations (Carbonnell et al. 2013), which is also in line with the notion that N-40 indexes response selection processes; (5) the procedure used here was efficient in inducing a clear ATPD, known to induce a secondary dopamine depletion (McTavish et al. 
Fig. 2 N-40: in black, the placebo session and in gray, the APTD session; in dash, the congruent condition and in solid the incongruent condition. Maps have the same scale and dated at $-30 \mathrm{~ms}$. The zero of time corresponds to the onset of the EMG burst

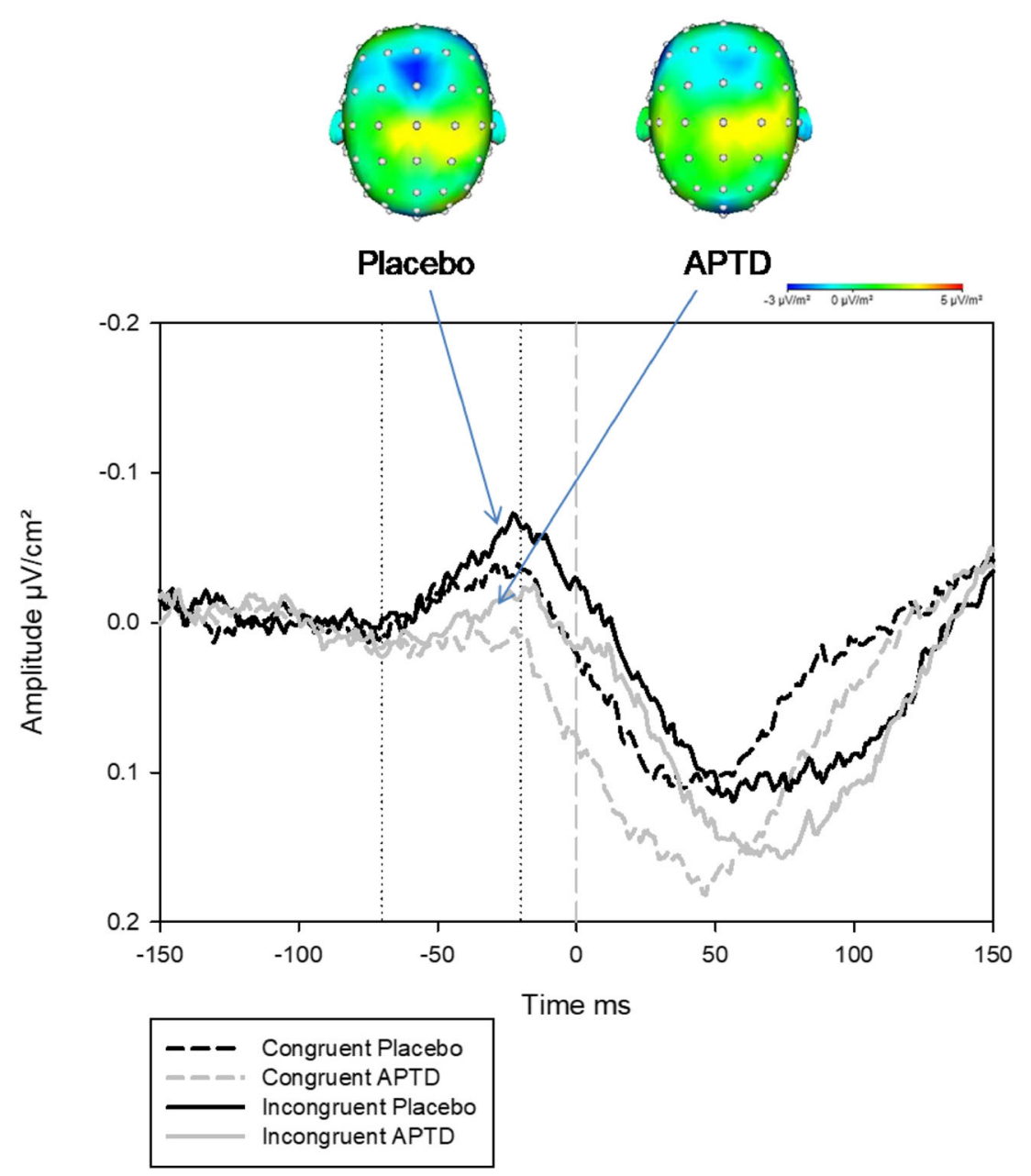

1999; Leyton et al. 2000, 2004; Nagano-Saito et al. 2008, 2012); (6) acute dopamine depletion had no effect on RT, error rate, or the size of the congruency effect, in line with Larson et al.'s (2015) results who did not evidence either any APTD effect on RT, error rates, or the size of the congruency effect, in another conflict task.

Therefore, given that the procedure used here induced a clear APTD, and that subjects exhibited behavioral and EEG patterns as expected from previous literature, we can be quite confident that subjects were submitted to classical appropriate experimental conditions.

In these conditions, (1) over M1s, neither contralateral activation nor ipsilateral inhibition were sensitive to congruency, suggesting that congruency has little or no effect on execution processes (contralateral M1) or error prevention (ipsilateral M1); (2) over M1s, neither contralateral activation nor ipsilateral inhibition were sensitive to APTD, suggesting that the dopamine depletion has little or no effect on execution processes (contralateral M1) or error prevention (ipsilateral M1); (3) over the SMAs, the N-40 was reduced after APTD, suggesting that the dopamine depletion affects response selection processes.
A first comment is in order. The sensitivity of the N-40 to ATPD cannot be attributed to a general effect on cerebral electrogenesis. First, because ERPs recorded over M1s were unaffected by ATPD; secondly, because Larson and his colleagues (2015) examined extensively the sensitivity to ATPD of several ERPs, assumed to reveal action monitoring processes, namely the N450 (West and Alain 2000), the conflict slow potential (West and Alain 2000; McNeely et al. 2003), the Error Negativity (Falkenstein et al. 1991; Gehring et al. 1993), or the Error Positivity (Falkenstein et al. 1991), and none of these activities were sensitive to ATPD, thus confirming that the present effects observed on the N-40 cannot result from a general decrease of electrogenesis. Therefore, one can conclude that the sensitivity of the N-40 to ATPD is specific.

Second, because dopamine depletion has little or no effect on execution processes (contralateral M1) or proactive control of errors (ipsilateral M1), one can conclude that the effect of ATPD observed on the N-40 over the SMAs reflects a selective influence of dopamine depletion on response selection processes (as proposed in the "Introduction" section), without noticeable effects on processes occurring downstream, i.e., 
Fig. 3 Activation/inhibition pattern: In green, the placebo session; light green: activation of the (contralateral) primary motor cortex involved in the response; and dark green: inhibition of the (contralateral) primary motor cortex involved in the response. In red, the APTD session; dark red: activation of the (contralateral) primary motor cortex involved in the response; and light red: inhibition of the (ipsilateral) primary motor cortex involved in the response. The zero of time corresponds to the onset of the EMG burst. Maps have the same scale and dated at $0 \mathrm{~ms}$. On the left side of maps, in blue, the activity of controlateral primary motor cortex involved in the response and on the right side of the map, in red, the activity of ipsilateral primary motor cortex involved in the response

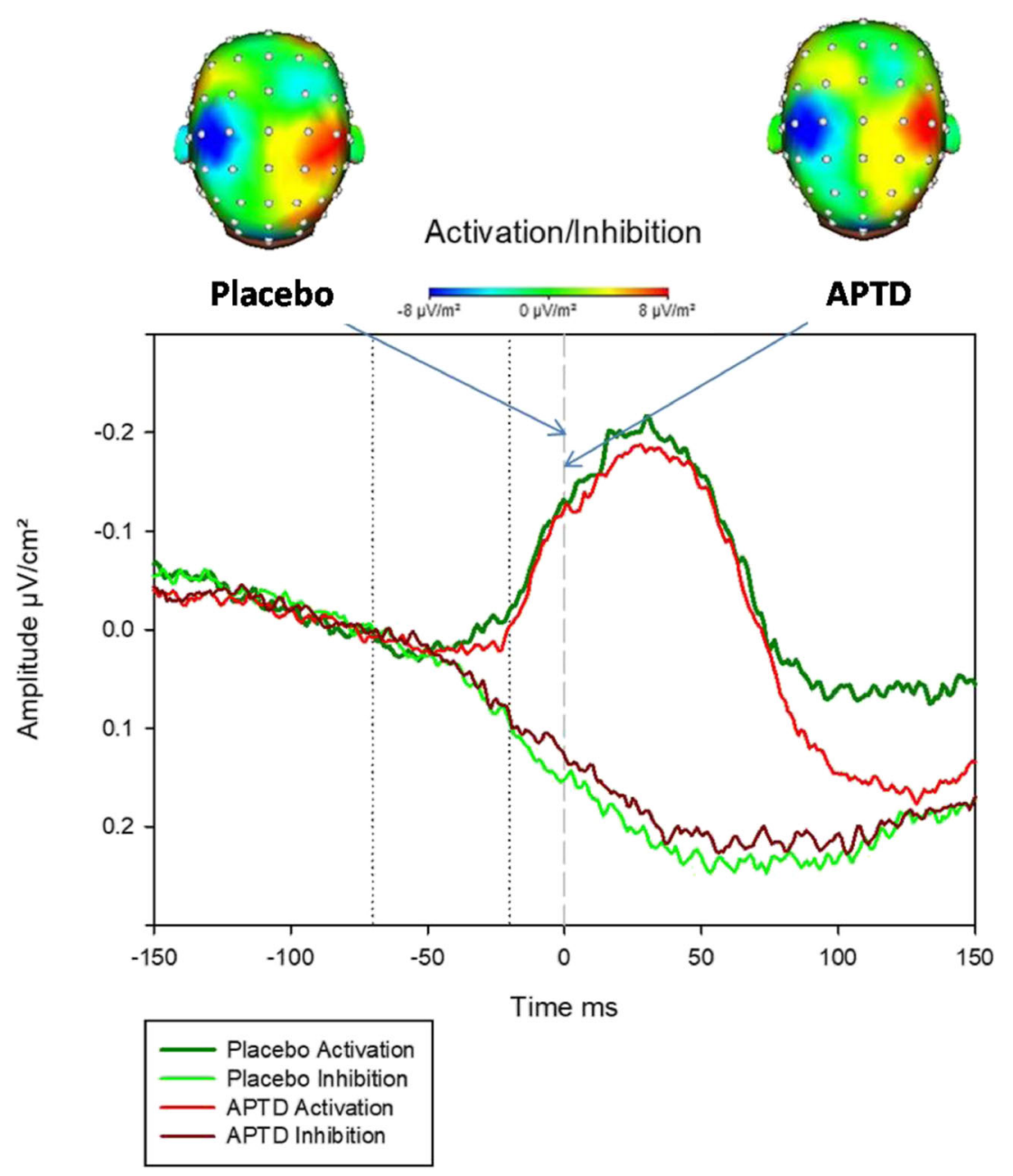

response execution. Note that the selective influence of APTD, but also of congruency, on upstream processes, both leaving unaffected contingent downstream activities, suggests the existence of separate modules in information processing operations (Sternberg 2001, 2011) and the existence of "functionally specialized [neural] processing modules" (Sternberg 2011, page 158).

Now, because APTD had no influence on RT, error rate, or the size of the congruency effect (Ramdani et al. 2015; Larson et al. 2015), we must conclude that the effect of an about $30 \%$ dopamine depletion (Leyton et al. 2004; Montgomery et al. 2003) observed here on the N-40 reveals a weak infraclinical functional deficit in response selection operations. One can imagine that a stronger depletion would have a behavioral expression on RTs.

According to the model of Keeler et al. (2014), fMRI data reported by Yoon et al. (2015) indicate that during the preparatory period of a choice RT task, the dopaminergic system is involved in preparing for response selection; the SN pars compacta BOLD signal increased after the precue but returned to baseline before the end of the preparatory period in the easiest of the two possible response selection conditions.
However due to the low temporal resolution of fMRI, no evidence could be provided regarding response selection per se.

If one admits that the $\mathrm{N}-40$ is a physiological index of response selection processes (Vidal et al. 2011; Carbonnell et al. 2013), the selective sensitivity of the N-40 to ATPD, with spared M1s activation/inhibition pattern, lends support to the model of Keeler et al. (2014) which assumes that the dopaminergic system is involved in response selection per se. In the motor loop between the basal ganglia and the cortex (Alexander and Crutcher 1990), the SMAs constitute a major cortical target of the basal ganglia, via the thalamus. If we assume that the N-40 is generated by the SMAs (Carbonnell et al. 2013), it is likely that the final effect of dopaminergic depletion on response selection takes place in the SMAs because of a decrease in thalamic glutamatergic output to this area, due to dopamine depletion-induced striatal impairment. Of course, it cannot be excluded that APTD influenced SMAs activity through direct dopaminergic projections to the cortex; however, this seems unlikely since PET studies show that most of the APTD-induced dopamine depletion involves striatal structures (Leyton et al. 2004; Montgomery et al. 2003). 
According to Grillner and his colleagues $(2005,2013)$, the basal ganglia are strongly involved in the selection of basic motor programs (e.g., locomotion, chewing, swallowing, eye movements...), through a basic organization that has been conserved throughout vertebrate phylogeny, from lamprey to primates. The model of Keeler et al. (2014), the data of Yoon et al. (2015), and the present results suggest that the implication of basal ganglia in action selection might also concern more flexible experience-dependent motor programs.

A final comment is in order. Although the Laplacian transformation largely increases the spatial resolution of EEG data, it is not possible to spatially separate the subregions of SMAs, i.e., the pre-SMA and SMA proper (Luppino et al. 1991; Matsuzaka et al. 1992; Picard and Strick 1996, 2001). Larson et al. (2015) reported that APTD does not affect the Error Negativity (note that we did not evidence either any effect of APTD on the Error Negativity in the present experiment [data not shown]). Now, it has been demonstrated with intracerebral electroencephalography in human subjects that the Error Negativity is primarily generated in SMA proper but not in pre-SMA (Bonini et al. 2014). This suggests that SMA proper activity is not noticeably impaired by ATPD. As a consequence, it seems likely that the $\mathrm{N}-40$ is generated in the pre-SMA. Although both areas receive disynaptic inputs from the basal ganglia via the thalamus, a differential sensitivity of SMA proper and pre-SMA to dopamine depletion is not necessarily surprising if one considers that preSMA and SMA proper are targeted by neurons located in neurochemically and spatially distinct regions of the internal segment of the globus pallidus (Akkal et al. 2007), a major output structure of the basal ganglia.

Two limitations of the present study must be noticed.

First, considering that the model of Keeler et al. (2014) not only assumes that the dopaminergic system is involved in response selection but also supposes that response selection of the appropriate response is achieved via the D2 system, the present study is unable to determine whether the effects of dopamine depletion are due to D1, D2 subreceptor types, or both; the same remark would also hold for Yoon et al. (2015) results. Secondly, our ATPD manipulation is an all or none one, with no possibility to evidence "dose-dependent effects." Future pharmacological manipulations would allow dose-dependent manipulations with possibly no behavioral effects at lower doses and behavioral impairments at higher doses. Such manipulations would also allow separating at least in part D2 from D1 effects to test further the model of Keeler et al. (2014).

To conclude, our results extend those of Yoon, who showed in a fMRI study that the dopaminergic system was finely sensitive to the complexity/simplicity of response selection during preparation. Thanks to the N-40, in accordance with the model of Keeler et al. (2014), the present results directly indicate that the dopaminergic system is selectively involved in response selection per se, with little or no effect on response execution processes or proactive control of errors.
Acknowledgements We thank Dominique Reybaud, Bruno Schmid, and the pharmacy personnel of the hospital Sainte Anne for their helpful technical contribution.

Funding information The authors also gratefully acknowledge the financial support from the Institut de Recherches Biomédicales des Armées, France.

\section{Compliance with ethical standards}

Conflict of interest The authors declare that they have no conflict of interest.

\section{References}

Akkal D, Dum RP, Strick PL (2007) Supplementary motor area and presupplementary motor area: targets of basal ganglia and cerebellar output. J Neurosci 27(40):10659-10673. https://doi.org/10.1523/ JNEUROSCI.3134-07.2007

Alexander GE, Crutcher MD (1990) Functional architecture of basal ganglia circuits: neural substrates of parallel processing. Trends Neurosci 13(7):266-271. https://doi.org/10.1016/0166-2236(90) 90107-L

Amengual JL, Marco-Pallarés J, Grau C, Münte TF, RodríguezFornells A (2014) Linking motor-related brain potentials and velocity profiles in multi-joint arm reaching movements. Front Hum Neurosci 8:271

Arezzo J, Vaughan HG Jr (1980) Intracortical sources and surface topography of the motor potential and somatosensory evoked potential in the monkey. Prog Brain Res 54:77-83. https://doi.org/10.1016/ S0079-6123(08)61610-6

Bonini F, Burle B, Liégeois-Chauvel C, Régis J, Chauvel P, Vidal F (2014) Action monitoring and medial frontal cortex: leading role of supplementary motor area. Science 343(6173):888-891. https:// doi.org/10.1126/science.1247412

Brown VJ, Robbins TW (1991) Simple and choice reaction time performance following unilateral striatal dopamine depletion in the rat. Brain 114(1):513-525. https://doi.org/10.1093/brain/114.1.513

Carbonnell L, Ramdani C, Meckler C, Burle B, Hasbroucq T, Vidal F (2013) The N-40: an electrophysiological marker of response selection. Biol Psychol 93(1):231-236. https://doi.org/10.1016/j. biopsycho.2013.02.011

Carvalhaes C, de Barros JA (2015) The surface Laplacian technique in EEG: theory and methods. Int J Psychophysiol 97(3):174-188. https://doi.org/10.1016/j.ijpsycho.2015.04.023

Coull JT, Cheng RK, Meck WH (2011) Neuroanatomical and neurochemical substrates of timing. Neuropsychopharmacology 36(1): 3-25. https://doi.org/10.1038/npp.2010.113

Coull JT, Hwang HJ, Leyton M, Dagher A (2012) Dopamine precursor depletion impairs timing in healthy volunteers by attenuating activity in putamen and supplementary motor area. J Neurosci 32(47): 16704-16715. https://doi.org/10.1523/JNEUROSCI.1258-12.2012

Deecke L, Grözinger B, Kornhuber HH (1976) Voluntary finger movement in man: cerebral potentials and theory. Biol Cybern 23(2):99 119. https://doi.org/10.1007/BF00336013

Falkenstein M, Hohnsbein J, Hoormann J, Blanke L (1991) Effects of crossmodal divided attention on late ERP components. II. Error processing in choice reaction tasks. Electroencephalogr Clin Neurophysiol 78(6):447-455. https://doi.org/10.1016/00134694(91)90062-9 
Gehring WJ, Goss B, Coles MGH, Meyer DE, Donchin E (1993) A neural system for error detection and compensation. Psychol Sci 4(6):385-390. https://doi.org/10.1111/j.1467-9280.1993.tb00586.x

Giard MH, Besle J, Aguera PE, Gomot M, Bertrand O (2014) Scalp current density mapping in the analysis of mismatch negativity paradigms. Brain Topogr 27(4):428-437. https://doi.org/10.1007/ s10548-013-0324-8

Gratton G, Coles M, Donchin E (1983) A new method for off-line removal of ocular artifact. Electroencephalogr Clin Neurophysiol 55(4):468-484. https://doi.org/10.1016/0013-4694(83)90135-9

Grillner S, Hellgren J, Menard A, Saitoh K, Wikström MA (2005) Mechanisms for selection of basic motor programs - roles for the striatum and pallidum. Trends Neurosci 28(7):364-370. https://doi. org/10.1016/j.tins.2005.05.004

Grillner S, Robertson B, Stephenson-Jones M (2013) The evolutionary origin of the vertebrate basal ganglia and its role in action selection. J Physiol 591(22):5425-5431. https://doi.org/10.1113/jphysiol.2012.246660

Hommel B, Proctor RW, Vu KP (2004) A feature-integration account of sequential effects in the Simon task. Psychol Res 68(1):1-17. https:// doi.org/10.1007/s00426-003-0132-y

Kayser J, Tenke CE (2015) On the benefits of using surface Laplacian (current source density) methodology in electrophysiology. Int $\mathrm{J}$ Psychophysiol 97(3):171-173. https://doi.org/10.1016/j.ijpsycho. 2015.06.001

Keeler JF, Pretsell DO, Robbins TW (2014) Functional implications of dopamine D1 vs. D2 receptors: a 'prepare and select' model of the striatal direct vs. indirect pathways. Neuroscience 282:156-175. https://doi.org/10.1016/j.neuroscience.2014.07.021

Kornblum S, Stevens GT, Whipple A, Requin J (1999) The effects of irrelevant stimuli: the time course of S-S and S-R consistency effects with Stroop-like stimuli, Simon-like tasks, and their factorial combinations. J Exp Psychol Hum Percept Perform 25:688-714

Larson MJ, Clayson PE, Primosch M, Leyton M, Steffensen SC (2015) The effects of acute dopamine precursor depletion on the cognitive control functions of performance monitoring and conflict processing: an event-related potential (ERP) study. PLoS One 10(10): e0140770. https://doi.org/10.1371/journal.pone.0140770

Leyton M, Young SN, Pihl RO, Etezadi S, Lauze C, Blier P, Baker GB, Benkelfat C (2000) Effects on mood of acute phenylalanine/tyrosine depletion in healthy women. Neuropsychopharmacology 22(1):52-63

Leyton M, Dagher A, Boileau I, Casey K, Baker GB, Diksic M, Gunn R, Young SN, Benkelfat C (2004) Decreasing amphetamine-induced dopamine release by acute phenylalanine/tyrosine depletion: a PET/ $\left[{ }^{11} \mathrm{C}\right]$ raclopride study in healthy men. Neuropsychopharmacology 29(2):427-432. https://doi.org/10.1038/sj.npp.1300328

Luppino G, Matelli M, Camarda RM, Gallese V, Rizzolatti G (1991) Multiple representations of body movements in mesial area 6 and the adjacent cingulate cortex: an intracortical microstimulation study in the macaque monkey. J Comp Neurol 311(4):463-482. https:// doi.org/10.1002/cne. 903110403

Matsuzaka Y, Aizawa H, Tanji J (1992) A motor area rostral to the supplementary motor area (presupplementary motor area) in the monkey: neuronal activity during a learned motor task. J Neurophysiol 68(3):653-662. https://doi.org/10.1152/jn.1992.68.3.653

McNeely HE, West R, Christensen BK, Alain C (2003) Neurophysiological evidence for disturbances of conflict processing in patients with schizophrenia. J Abnorm Psychol 112(4):679-688. https://doi.org/10.1037/0021-843X.112.4.679

McTavish SF, Cowen PJ, Sharp T (1999) Effect of a tyrosine-free amino acid mixture on regional brain catecholamine synthesis and release. Psychopharmacology 141(2):182-188. https://doi.org/10.1007/ s002130050823

Meckler C, Allain S, Carbonnell L, Hasbroucq T, Burle B, Vidal F (2010) Motor inhibition and response expectancy: a Laplacian ERP study. Biol Psychol 85(3):386-392. https://doi.org/10.1016/j.biopsycho. 2010.08.011
Montague PR, Dayan P, Sejnowski TJ (1996) A framework for mesencephalic dopamine systems based on predictive Hebbian learning. J Neurosci 16(5):1936-1947

Montague PR, Hyman SE, Cohen JD (2004) Computational roles for dopamine in behavioural control. Nature 431(7010):760-767. https://doi.org/10.1038/nature03015

Montgomery AJ, McTavish SF, Cowen PJ, Grasby PM (2003) Reduction of brain dopamine concentration with dietary tyrosine plus phenylalanine depletion: an ${ }^{[11 \mathrm{C}]}$ raclopride PET study. Am J Psychiatry 160(10):1887-1889

Mostofsky SH, Simmonds DJ (2008) Response inhibition and response selection: two sides of the same coin. J Cogn Neurosci 20(5):751761. https://doi.org/10.1162/jocn.2008.20500

Nagano-Saito A, Leyton M, Monchi O, Goldberg YK, He Y, Dagher A (2008) Dopamine depletion impairs frontostriatal functional connectivity during a set-shifting task. J Neurosci 28(14):3697-3706. https://doi.org/10.1523/JNEUROSCI.3921-07.2008

Nagano-Saito A, Cisek P, Perna AS, Shirdel FZ, Benkelfat C, Leyton M, Dagher A (2012) From anticipation to action, the role of dopamine in perceptual decision making: an fMRI-tyrosine depletion study. J Neurophysiology 108(2):501-512. https://doi.org/10.1152/jn. 00592.2011

Nuñez PL (1989) Estimation of large scale neocortical source activity with EEG surface Laplacians. Brain Topogr 2(1-2):141-154

Perrin F, Bertrand O, Pernier J (1987) Scalp current density mapping: value and estimation from potential data. IEEE Trans Biomed Eng 34(4):283-288

Picard N, Strick PL (1996) Motor areas of the medial wall: a review of their location and functional activation. Cereb Cortex 6(3):342-353. https://doi.org/10.1093/cercor/6.3.342

Picard N, Strick PL (2001) Imaging the premotor areas. Curr Opin Neurobiol 11(6):663-672. https://doi.org/10.1016/S0959-4388(01)00266-5

Proctor RW, Reeve TG (Eds.) (1990) Stimulus-response compatibility: an integrated perspective. Amsterdam: North-Holland

Ramdani C, Carbonnell L, Vidal F, Béranger C, Dagher A, Hasbroucq T (2015) Dopamine precursors depletion impairs impulse control in healthy volunteers. Psychopharmacology 232(2):477-487. https:// doi.org/10.1007/s00213-014-3686-Z

Rogers RD (2011) The roles of dopamine and serotonin in decision making: evidence from pharmacological experiments in humans. Neuropsychopharmacology 36(1):114-132. https://doi.org/10. 1038/npp.2010.165

Sejnowski T, Churchland P (1990) Brain and cognition. In: Posner M (ed) Foundations of cognitive sciences. MIT Press, Cambridge

Simon JR (1990) The effects of an irrelevant directional cue on human information processing. In: Reeve RWPTG (ed) Stimulus-response compatibility. North-Holland, Elsevier Science Publishers, pp 31-86

Staude GH (2001) Precise onset detection of human motor responses using a whitening filter and the log-likelihood-ratio test. IEEE Trans Biomed Eng 48(11):1292-1305. https://doi.org/10.1109/10.959325

Sternberg S (2001) Separate modifiability, mental modules, and the use of pure and composite measures to reveal them. Acta Psychol (Amst) 106(1-2):147-246. https://doi.org/10.1016/S0001-6918(00)00045-7

Sternberg S (2011) Modular processes in mind and brain. Cognitive neuropsychology 28(3-4):156-208. https://doi.org/10.1080/02643294. 2011.557231

Van Boxtel GJM, Geraats LHD, Van den Bref-Lessen MMC, Brunia CHM (1993) Detection of EMG onset in ERP research. Psychophysiology 30(4):405-412. https://doi.org/10.1111/j.14698986.1993.tb02062.x

Van de Laar MC, van den Wildenberg WP, van Boxtel GJ, Huizenga HM, van der Molen MW (2012) Lifespan changes in motor activation and inhibition during choice reactions: a Laplacian ERP study. Biol Psychol 89(2):323-334. https://doi.org/10.1016/j.biopsycho.2011. 11.005 
Vidal F, Burle B, Grapperon J, Hasbroucq T (2011) An ERP study of cognitive architecture and the insertion of mental processes: Donders revisited. Psychophysiology 48(9):1242-1251. https://doi. org/10.1111/j.1469-8986.2011.01186.x

West R, Alain C (2000) Effects of task context and fluctuations of attention on neural activity supporting performance of the Stroop task. Brain Res 873(1):102-111. https://doi.org/10.1016/S0006-8993(00)02530-0
Yoon JH, Larson P, Grandelis A, La C, Cui E, Carter CS, Minzenberg MJ (2015) Delay period activity of the substantia nigra during proactive control of response selection as determined by a novel fMRI localization method. J Cogn Neurosci 27(6):1238-1248. https://doi.org/ 10.1162/jocn a 00775 